\title{
Dynamics of Defects and Surface Structure Formation in Reticulated Vitreous Carbon
}

\author{
E. S. Gonçalves ${ }^{1,2}$, M. C. Rezende ${ }^{1}$, and N. G. Ferreira ${ }^{3}$ \\ ${ }^{1}$ Divisão de Materiais, Instituto de Aeronáutica e Espaço, \\ ${ }^{2}$ Instituto Tecnológico da Aeronáutica Centro Técnico Aeroespacial, Praça Marechal Eduardo Gomes, \\ 50 - Vila das Acácias 12228-904, São José dos Campos-SP, Brazil and \\ ${ }^{3}$ Laboratório Associado de Sensores e Materiais, Instituto Nacional de Pesquisas Espaciais, \\ Caixa Postal 515, 12245-970 São José dos Campos-SP, Brazil
}

Received on 1 April, 2005

\begin{abstract}
Morphological and microstructure properties of reticulated vitreous carbon (RVC) were analyzed by scanning electron microscopy (SEM), micro-Raman spectroscopy and x-ray diffraction (XRD) techniques as a function of heat treatment temperature (HTT). Samples produced in the HTT range of 1000 to $2400 \mathrm{~K}$ have demonstrated a strong dependence of HTT in their structural order mainly attributed to the presence of hydrogen and oxygen (heteroatoms), originated from precursor. In this range, the material is changed from pyropolymer to carbon. The polyfurfuryl alcohol precursor has furanic groups and its cure originates methylenical bonds and sulphur atoms. At HTT higher than $1300 \mathrm{~K}$, these atoms are gradually liberated from the material generating a discrete structure ordering.
\end{abstract}

Keywords: Defects; Surface Structure; Vitreous carbon

\section{INTRODUCTION}

Reticulated vitreous carbon (RVC) is an important material known by its high mechanical resistance, porosity, biocompatibility and relatively high electric conductivity. The morphological and structural properties of such singular material have been extensively explored in the last decades, mainly due to their wide range of applications, for example, in thermal coating of airships [1,2], bony prostheses [3], heart valves [4-6], molecular sieves [7], hydrogenation catalyst supports [8], among others. Besides, RVC has a low density and high electrical conductivity [9] that is very attractive for electrochemical applications as three-dimensional electrode [10]. Electric conductivity variation is a determinant parameter for using RVC electrodes in many electrochemical applications. The proportional increase of conjugated carbon in the $\mathrm{sp}^{2}$ state during pyrolysis would change the material progressively from an insulator to a good conductor in the remarkable range of 19 orders of magnitude. The electrical properties will afford, therefore, a sensitive measure of various stages of pyrolysis and provide information on the structure of the final carbon [6].

RVC samples are usually produced from thermosetting resins used to impregnate polyurethane foams. The resin on the foam is hardened through curing reaction and can be carbonized at different heat treatment temperature (HTT).

The goal of this work is to describe systematically morphological and structural properties of RVC three dimensional samples, produced from furfurylic resin at different HTT. The discussions will report the importance of thermal treatment related to its strong dependence for the microstructural properties of this material, as pilling up width of layers $\left(L_{002}\right)$, interlayer distance $\left(d_{002}\right)$, from x-ray diffraction measurements (XRD) [11-13]. In addiction, the relative intensity of $D$ and $\mathrm{G}$ bands associated with their ratio and FWHM analyses from Raman spectra have corroborated the XRD results.

\section{EXPERIMENTAL}

RVC was obtained from polyurethane (PU) foam based on polyether impregnated with furfuryl resin. The resin curing process needs to use p-toluenossulfonic acid as catalyst, at $3 \% \mathrm{w} / \mathrm{w}$. The complete curing occurred after two hours at 360 and $400 \mathrm{~K}$, assuring mechanical resistance to material. Each sample is submitted to a heat treatment process for obtaining RVC. They are heated at $1 \mathrm{~K} \cdot \mathrm{min}^{-1}$, under inert atmosphere with nitrogen flow of $1{\mathrm{~L} . \mathrm{h}^{-1}}^{-1}$, reaching the maximum temperature of 1000, 1300, 1600, 1800, 2100 and 2300 $\mathrm{K}$, holding at this maximum temperature during $30 \mathrm{~min}$ and then cooling down to room temperature. The furfuryl resin used in this work is a national polymer and promotes denser final carbonized foam due to lower losses in volatiles cure and carbonization processes. This resin produces a material more electrically conductive and resistant to flexion than RVC obtained from phenolic resin [14].

A LEO 440 scanning electron microscope was used to observe RVC morphology and a Renishaw Microscope system 2000 in backscattering configuration at room temperature employing $514.5 \mathrm{~nm}$ argon-ion laser to obtain micro-Raman spectra. This powerful and sensible technique permits an analysis of impurities and defects, especially the ones associated to graphitic phases. XRD measurements were performed from a diffractometer Phillips, PW 1210/W/380/80.

\section{RESULTS AND DISCUSSION}

Images obtained by scanning electron microscopy (SEM) do not reveal large differences among struts for samples at different HTT. SEM images with magnification of 40 times are shown in Fig. 1. This image permits to estimate the pores diameter as the way to quantify such pores per inch (ppi) on RVC samples. Pores with average diameter of $300 \mu \mathrm{m}$ were 
formed, corresponding to $70 \mathrm{ppi}$. This value is important to estimate the specific geometric surface area. Friedrich et al [9] have measured the strut areas of such pores by SEM and found a linear relation between the quantity of ppi and the specific surface area. By using this relation, it was evaluated for $70 \mathrm{ppi}$, a volumetric specific area of around $45 \mathrm{~cm}^{2} \mathrm{~cm}^{-3}$.

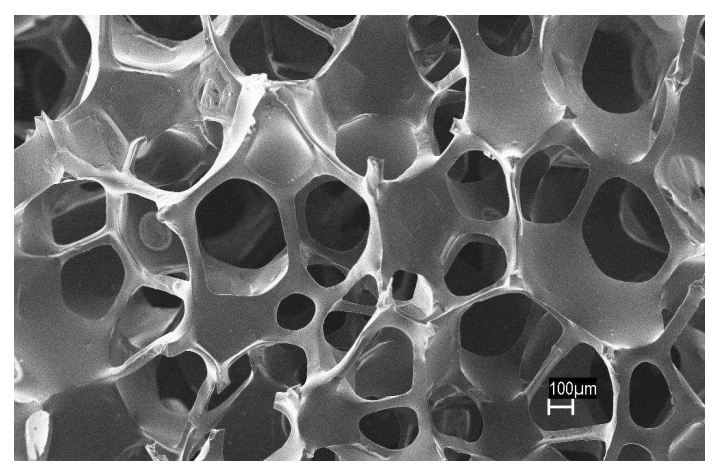

FIG. 1: SEM image of RVC sample treated at $1300 \mathrm{~K}$.

For discussing the microstructural properties of RVC samples it is very important a systematic interpretation of XRD and Raman measurements in the whole range of studied temperatures. After carbonization process, RVC is a low volume disordered glassy porous carbon with a continuous skeletal structure, low resistance and some crystallographic order associated to its graphitization index [9]. RVC structures, also called turbostract carbon (TC), have their microstructure formed by disordered, no planar and confluent graphitic ribbons. Figure 2 shows the pilling up width $\left(L_{002}\right)$ and interplanar distance $\left(d_{002}\right)$ as a function of HTT for RVC samples, as already studied by other authors $[11,13,15]$. Hydrogen and oxygen (heteroatoms) presence originated from precursor represents a contribution in surface interaction process [16], mainly for lower HTT [12]. This behavior justifies the intense decrease of $d_{002}$ at range of $1000-1300 \mathrm{~K}$, accomplished by increase of $L_{002}$ due to the heteroatoms release.

In deed, this process concerns to the liberation of relatively large atoms as oxygen or nitrogen originated from precursor. This liberation occurs up to $1300 \mathrm{~K}$ where a significant decrease of intralamellar distance appears. The more important contributions concerning to the TC organization was observed for HTT higher than $1500 \mathrm{~K}$ [17]. It is possible to observe this process in X-ray response at HTT higher than $1300 \mathrm{~K}$, with $L_{002}$ increase and $d_{002}$ decrease. Additional contribution for $L_{002}$ increase is attributed to lamella estrangement.

Micro-Raman spectra for RVC substrate produced at 2300 $\mathrm{K}$ are shown in Fig. 3. RVC curve has a typical two bands spectrum of disordered polycrystalline and noncrystalline graphitic carbons [18]. The first one, at approximately $1360 \mathrm{~cm}^{-1}$, exists only in defective carbons and is called "Dband", associated to disorder and edges of these crystals. The band at $1600 \mathrm{~cm}^{-1}$ can always be presented in vitreous carbon as a superposition of two components: $\mathrm{G}\left(1580 \mathrm{~cm}^{-1}\right)$ and D'

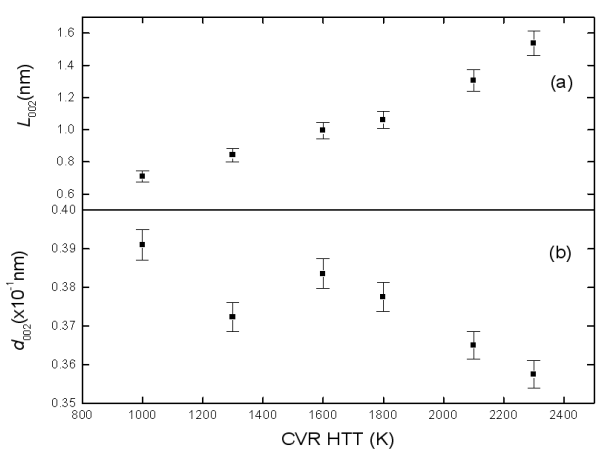

FIG. 2: (a) Pilling up width $\left(L_{002}\right)$ and (b) interplanar distance $\left(d_{002}\right)$ evaluated from XRD on RVC samples as a function of HTT.

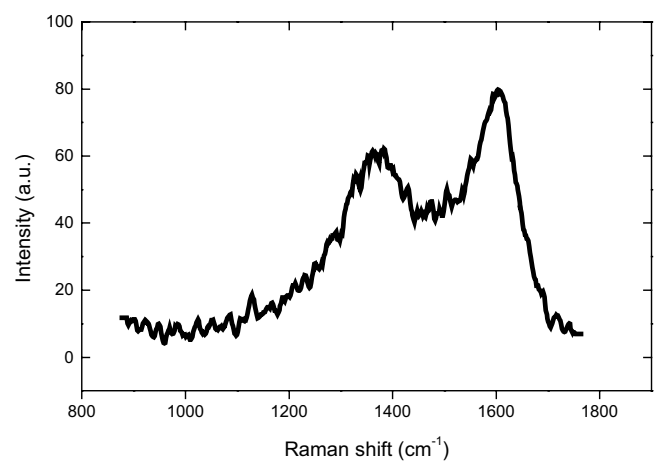

FIG. 3: Raman spectra of: (a) RVC sample treated at $1400 \mathrm{~K}$.

$\left(1620 \mathrm{~cm}^{-1}\right)$ [13]. The G-band is called "graphitic" and attributed to the graphite basal plane. On the other hand, the D' band is attributed to second first order zone boundary phonon [18].

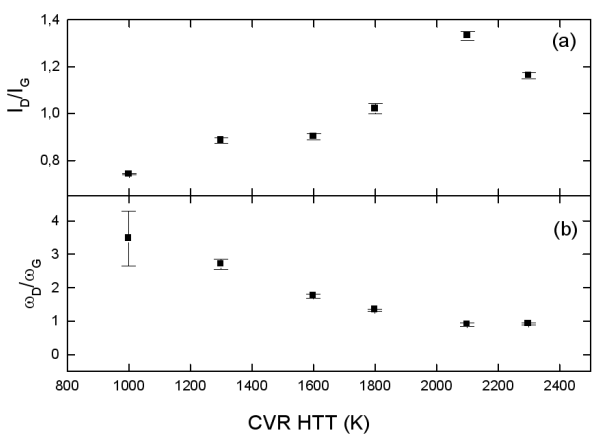

FIG. 4: (a) Relative intensity $\left(\mathrm{I}_{D} / \mathrm{I}_{G}\right)$ and (b) relative FWHM $\left(\omega_{D} / \omega_{G}\right)$ between D and G bands observed in the RVC Raman spectra as a function of HTT.

Figure 4 shows the ratio of $\mathrm{D}$ and $\mathrm{G}$ bands intensity and FWHM $\left(I_{D} / I_{G}\right.$ and $\omega_{D} / \omega_{G}$, respectively) from RVC Raman 
spectra as a function of HTT, to observe carbon disorder degree $[19,20]$. It is important to note that these results were not related with carbon crystallinity, since results obtained by first order Raman spectroscopy have restrictions to evaluate the crystalline changes [21].

However, mainly G-band FWHM is a strong indicative of the better ordering of the graphite basal plane that forms TC structure. In the temperature range between 1000 and $1300 \mathrm{~K}$, the $I_{D} / I_{G}$ increase may be related to structural defects attributed to heteroatoms release process living imperfect sites in their locations. Between 1300 and $1600 \mathrm{~K}$, there are not heteroatoms, and the $I_{D} / I_{G}$ increase is assimptotic, revealing an accommodation of lamellas in a structure with high graphitic character. Practically, this ratio does not vary until $1600 \mathrm{~K}$. In this temperature, warrant itself that there are not heteroatoms in the carbonous structure. Relative intensity of D-band continues increasing for HTT higher than 1300 $\mathrm{K}$, but between 1600 and $2100 \mathrm{~K}$ it is registered a significant increase. This contribution is mainly attributed to an additional process on stacking and approaching of lamellar surfaces, associated to TC confluence of such material. In addition, the $I_{D} / I_{G}$ decrease, observed above $2100 \mathrm{~K}$, may be associated to the initial stage of anisotropic structure formation process. The $\omega_{D} / \omega_{G}$ values present D-band FWHM decrease, also indicating disorder degree increase with HTT increase up to $2100 \mathrm{~K}$. These analyses agree with crystallinity results from XRD and indicate the contribution of heteroatoms until 1300 $\mathrm{K}$ and the predominance of TC formation above $1600 \mathrm{~K}$. In spite of to be studied in the literature the ratio $\omega_{D} / \omega_{G}$ go observe the graphitization quality [18], for this work the intensities evolution associated with D-band shift are more relevant.
This behavior is attributed to the formation of large reactivity sites [22].

It is important to highlight that $\mathrm{XRD}$ measurements are not necessarily related to Raman measurements. XRD offers data inherent to interlamellar structure, while Raman spectroscopy results relate aspects of intralamellar structure, observing phonon behavior. Thus, the narrowing of interlamellar distance, that indicates an ordering increase, is accomplished by defective sites appearance, as HTT increases. Thermodinamically, this is expected, since all entropy decrease in a system is accomplished by neighborhood entropy increase. It is, therefore, notable that the entropy decrease, at interlamellar system and revealed by $d_{002}$ behavior, compensated the entropy enhancement at intralamellar level, revealed by $I_{D} / I_{G}$ behavior.

\section{CONCLUSION}

Structural properties of RVC as a function of HTT were studied by Raman and XRD analysis. In this range of carbonization temperature (1000-2300 K) studied, different contributions are important to define $L_{002}$ and $d_{002}$ behaviors, which are in good correlation with D and $\mathrm{G}$ bands behaviors analyzed from Raman spectra. For HTT lower than $1500 \mathrm{~K}$, heteroatoms presence represents a dominant contribution in surface interaction process while the more important contributions concerning to the TC organization was observed for HTT higher than $1500 \mathrm{~K}$.

Acknowledgement This work was supported by FAPESP and CNPq.
[1] W. G. Bradshaw, P. C. Pinoli, and M. J. Mitchell, Recent Developments in glassy carbon fabrication. Extended abstracts, $9^{\text {th }}$ Biennial Conference on Carbon, Boston, MA. USA: American Carbon Society, 7, 1969.

[2] L.R. Bunnell, Proc. Vitreous carbon matrix carbon-carbon composite by copyrolysis. Extended abstracts, $12^{\text {th }}$ Biennial Conference on Carbon. Pennsylvania, USA: American Carbon Society, 333-334, 1975.

[3] R.B. Kaplan, Open cell tantalum structures for cancellous bone implants and cell and tissue receptors. US Patent 5282861, 1994.

[4] P. E. Ferrari, M. C. Rezende, R. C. Widner, R. A.di Iglia, M. F. B. Souza, and R. Bertazzoli, Utilização do carbono vítreo reticulado nacional para remoção de metais em descartes aquosos da indústria metal $/$ mecânica. $50^{\circ}$ Congresso Anual da $A B M$, 1995.

[5] J. C. Bokros, Carbon, 15, 353 (1977).

[6] G. M. Jenkins and C. J. Grigson, J. Biomed. Mater. Res.13, 371-394 (1979).

[7] J. L. Schmitt Jr. and P. L. Walker, Carbon, 10, 87 (1972).

[8] B. J. Cooper and D. L. Trimm In: Preprint $3^{\text {rd }}$ Conference on Industrial Carbon and Graphite, Soc. Chem. Ind., London, 1970.

[9] J. M. Friedrich, C. Ponce-de León, G. W. Reade. and F. C. Walsh. Journal of Electroanalytical Chemistry, 561, 203 (2004).
[10] X. Shui and D.D.L. Chung, Carbon 34, 811 (1996).

[11] S. Otani and A. Oya. In: R. W. Cahn, P. Haasen and E. J. Kramer, editors. Materials Science and Technology-A comprehensive treatment, vol 9, 1991.

[12] G. M. Jenkins and K. Kawamura. Polymeric Carbons-Carbon Fibre, Glass and Char. Cambridge University Press, Cambridge, 1976.

[13] L. A. Pesin, Journal of Materials Science 37, 1 (2002).

[14] M. C. Rezende, Produção de Carbono Vítreo em Escala de Laboratório a partir de Resinas Furfurílica e Fenólica. EPUSP, Universidade de São Paulo, Doctoral Thesis, 1991.

[15] F. Rousseaux and D. Tchoubar, Carbon 15, 63 (1977).

[16] F. Rousseaux and D.Tchoubar, Carbon 15, 55 (1977).

[17] C. A. Leon y Leon and L.R. In: P. A. Thrower, editor. Chemistry and physics of carbon, vol 24, Dekker, New York, 1994.

[18] D. S. Knight and W.B. White, Journal of Materials Research 4(2), 385 (1989).

[19] A. Cuesta, P. Dhamelincourt, J. Laureyns, A. Martinez-Alonso, and J.M.D., Journal of Materials Chemistry 8(12), 2875 (1998).

[20] A. C. Ferrari and J. Robertson, Physical Review B 61, 14095 (2000).

[21] Y.J. Lee, Journal of Nuclear Materials 325, 174 (2004).

[22] R. Bowling, R. T. Packard and R. L. Mc Creery, Langmuir 5, 683 (1989) 